\title{
THE LONG-TERM RESULTS OF STANMORE TOTAL KNEE REPLACEMENTS
}

\author{
A. W. F. LETTIN, T. G. KAVANAGH, J. T. SCALES
}

From the Institute of Orthopaedics, Royal National Orthopaedic Hospital, and St Bartholomew's Hospital, London

\begin{abstract}
Between 1969 and 197120 prototypes of the Stanmore total knee prosthesis were used to replace severely arthritic knees in 18 patients. Seven patients died before the final follow-up and one had to have her leg amputated because of deep infection; in none of these patients had the prosthesis become loose. Ten patients (11 knees) were reviewed at least 10 years after operation. There was no significant clinical deterioration in 7 of these 11 surviving knees when the results at one year were compared with those at 10 years.
\end{abstract}

The Stanmore hinged total knee prosthesis was introduced into clinical practice 30 years ago as a custommade prosthesis for the treatment of resectable malignant tumours around the knee (Burrows 1968; Scales and Lettin 1974; Burrows, Wilson and Scales 1975). The encouraging results led to the development of a hinged prosthesis for the replacement of arthritic knees (Wilson, Lettin and Scales 1974). We report the long-term results of a prototype of the Stanmore hinged prosthesis used in 18 patients with arthritis.

Table I. Age of patients

\begin{tabular}{|llc|}
\hline $\begin{array}{l}\text { Age } \\
\text { (years) }\end{array}$ & $\begin{array}{l}\text { Number } \\
\text { of patients }\end{array}$ & $\begin{array}{l}\text { Number } \\
\text { of knees }\end{array}$ \\
\hline$<40$ & 1 & 1 \\
$40-49$ & 1 & 1 \\
$50-59$ & 2 & 2 \\
$60-69$ & 8 & 10 \\
$70-80$ & 5 & 5 \\
$>80$ & 1 & 1 \\
\hline
\end{tabular}

MATERIALS AND METHOD

Eighteen arthritic patients who had knee replacements between October 1969 and November 1971 were followed up; two had both knees replaced. All were women aged between 37 and 87 years (Table I); only four, all with

A. W. F. Lettin, BSc, MS, FRCS, Consultant Orthopaedic Surgeon Royal National Orthopaedic Hospital, 234 Great Portland Street, London WIN 6AD, England.

T. G. Kavanagh, BSc, MB BS, FRCS, Senior Orthopaedic Registrar Department of Orthopaedics, St Bartholomew's Hospital, West Smithfield, London ECIA 7BE, England.

J. T. Scales, FRCS, Professor in Biomechanical Engineering Department of Biomedical Engineering, Institute of Orthopaedics, (University of London), Royal National Orthopaedic Hospital, Stanmore, Middlesex HA7 4LP, England.

Requests for reprints should be sent to Mr A. W. F. Lettin.

(C) 1984 British Editorial Society of Bone and Joint Surgery $0301-620 X / 84 / 3080 \$ 2.00$ severe rheumatoid arthritis, were less than 60 years old. Eight patients ( 10 knees) were affected by osteoarthritis and 10 (10 knees) by rheumatoid arthritis. Five knees had been operated on previously (Table II). One patient had previously fractured the tibia and fibula of the same leg.

Table II. Previous operations

\begin{tabular}{|ll|}
\hline Operation & Number of knees \\
\hline Tibial osteotomy & 2 \\
Patellectomy & 1 \\
Patellectomy and synovectomy & 1 \\
$\begin{array}{l}\text { Synovectomy and MacIntosh } \\
\text { surface replacement }\end{array}$ & 1 \\
\hline
\end{tabular}

All 20 knees were replaced with prostheses (Figs 1 and 2) made either from commercially pure titanium 160 with cobalt-chrome-molybdenum-alloy bearings, or entirely from cobalt-chrome-molybdenum alloy.

The operation was carried out using a medial parapatellar incision through the skin and the underlying capsule. After displacing the patella laterally, sufficient bone was resected from the lower end of the femur and the upper tibia to accommodate the body of the prosthesis and to correct any fixed deformity without disturbing the attachment of the patellar ligament. Sufficient cancellous bone was curetted from the medullary cavities to accept the stems of the prosthesis which were anchored to the bone with acrylic cement.

\section{RESULTS}

Survival. One patient died within a year of the operation after sustaining an intertrochanteric fracture of the femur on the same side as the knee replacement. This patient was, however, followed up until her death and the clinical and radiographic findings are included with the results 
of the remaining patients at one year. Six more patients, one with bilateral replacements, died between the second and the tenth year. One patient developed deep infection two years after replacement and had to have her leg amputated. After 10 years, 10 patients (with 11 prostheses) were still alive.

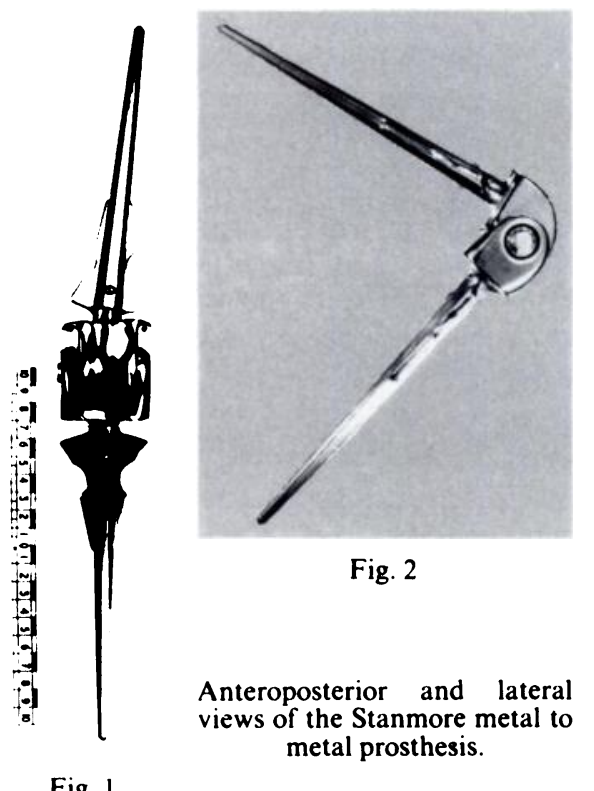

Pain. Before operation 20 knees were very painful on weight-bearing and nine were painful at rest. One year after operation, 16 were pain-free and only one of the painful knees required further treatment, the pain being associated with a laterally subluxating patella which was removed.

Of the 11 knees reviewed at 10 years or more, five were painful when rising from a chair; this pain appeared to be retropatellar in origin, but was not sufficiently troublesome to warrant treatment.

Table III. Patients with fixed deformity of greater than $10^{\circ}$

\begin{tabular}{|llll|}
\hline & & \multicolumn{2}{l|}{ After operation } \\
\cline { 3 - 4 } Deformity & $\begin{array}{l}\text { Before operation } \\
\text { (20 knees) }\end{array}$ & $\begin{array}{l}\text { 1 year } \\
\mathbf{( 2 0} \text { knees) }\end{array}$ & $\begin{array}{l}\text { 10 years } \\
\mathbf{( 1 1} \text { knees) }\end{array}$ \\
\hline Varus & 2 & 0 & 0 \\
Valgus & 12 & 0 & 0 \\
Flexion & 16 & 2 & 4 \\
\hline
\end{tabular}

Deformity. Sixteen knees had fixed flexion deformity of more than $10^{\circ}$ before they were replaced. There were two knees with fixed flexion deformities at one year, one associated with an arthrodesis and the other with a spontaneous ankylosis of the opposite knee in flexion. These deformities increased subsequently; one was corrected by operative posterior release, only to recur. At review 10 years after operation a further two knees had developed flexion deformities (Table III), one in an 80year-old who had become chairbound.
Range of flexion before operation

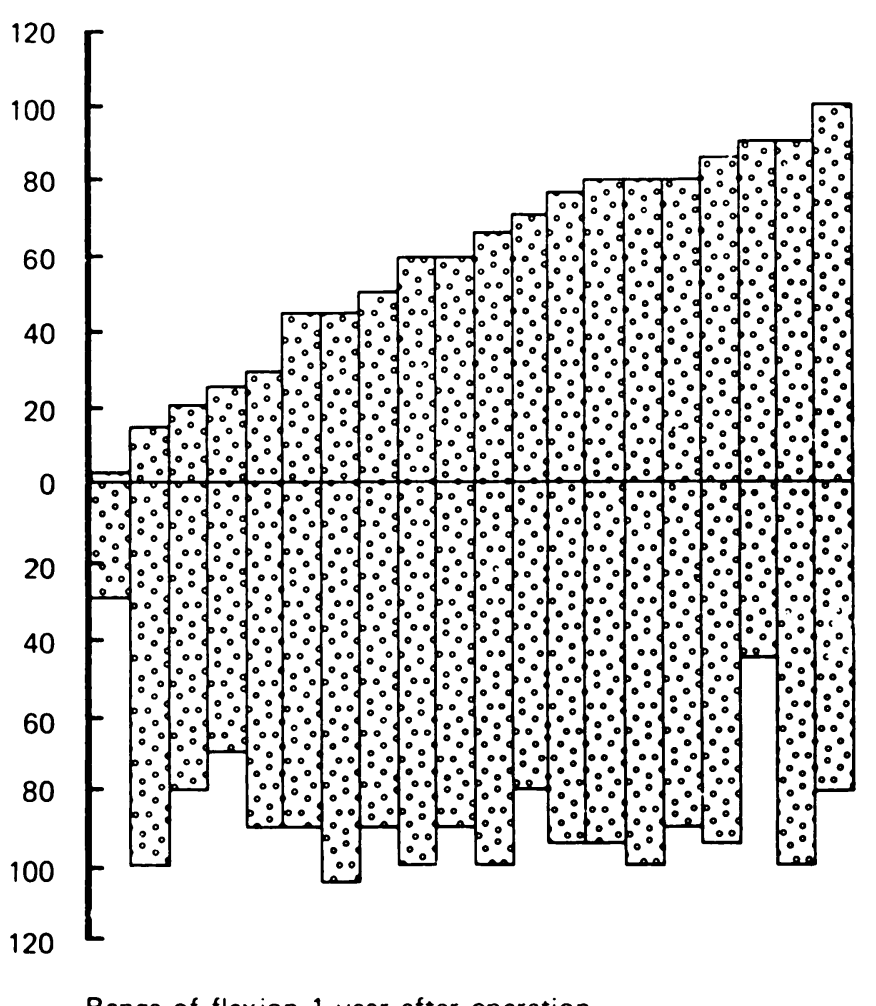

Range of flexion 1 year after operation

Fig. 3

Range of flexion before and one year after operation ( 20 knees).

Fourteen knees had $10^{\circ}$ or more of fixed varus or valgus deformity which was completely corrected by knee replacement; no varus or valgus deformities developed in the 11 knees reviewed at least 10 years after operation (Table III).

Stability. Ten knees were initially unstable when a varus or valgus force was applied in maximum extension, but all were stable after replacement and remained so.

Table IV. Range of movement

\begin{tabular}{|c|c|c|c|}
\hline \multirow[b]{2}{*}{$\begin{array}{l}\text { Range } \\
\text { (degrees) }\end{array}$} & \multirow[b]{2}{*}{$\begin{array}{l}\text { Before operation } \\
\text { (20 knees) }\end{array}$} & \multicolumn{2}{|c|}{ After operation } \\
\hline & & $\begin{array}{l}1 \text { year } \\
(20 \text { knees) }\end{array}$ & $\begin{array}{l}10 \text { years } \\
\text { (11 knees) }\end{array}$ \\
\hline$<40$ & 5 & 1 & 1 \\
\hline $40-59$ & 3 & 1 & 2 \\
\hline $60-79$ & 5 & 1 & 1 \\
\hline $80-100$ & 7 & 16 & 5 \\
\hline$>100$ & 0 & 1 & 2 \\
\hline
\end{tabular}

Movement. The range of flexion in every knee was limited before operation: in 10 knees it was $60^{\circ}$ or less (Fig. 3). After operation the range of flexion had improved in all but two instances, and in 17 knees it was $80^{\circ}$ or more (Table IV); the greatest increase in flexion was seen in the most severely affected knees. 
Flexion was maintained or improved in seven of the 11 knees reviewed at 10 years. Movement was lost completely in the patient whose opposite knee was arthrodesed, and reduced by recurrence of a $30^{\circ}$ flexion contracture in the patient whose opposite knee was ankylosed. The patient who became chairbound also developed flexion contractures which reduced movement (Fig. 4).

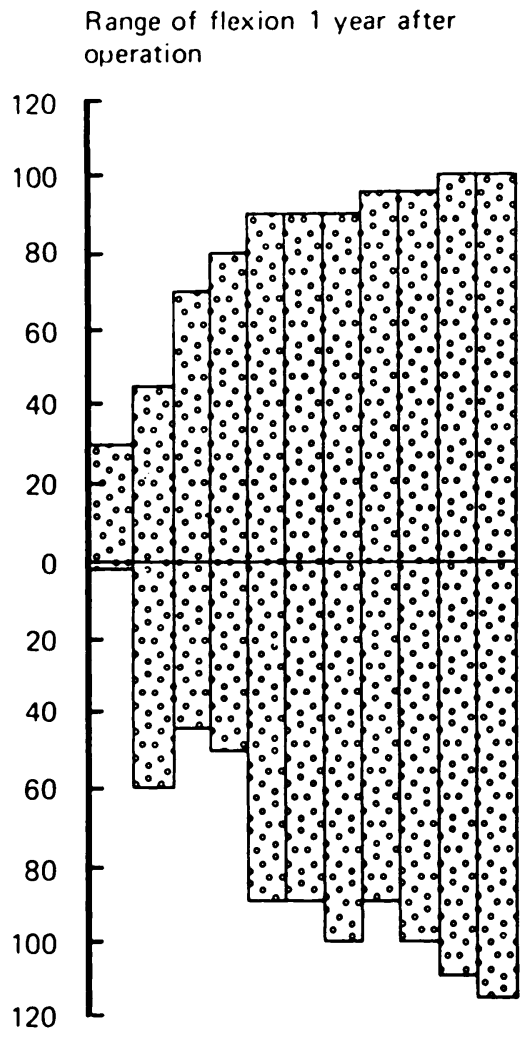

Range of flexion 10 years or more after operation

Fig. 4

Range of flexion one year and 10 years or more after operation (11 knees).

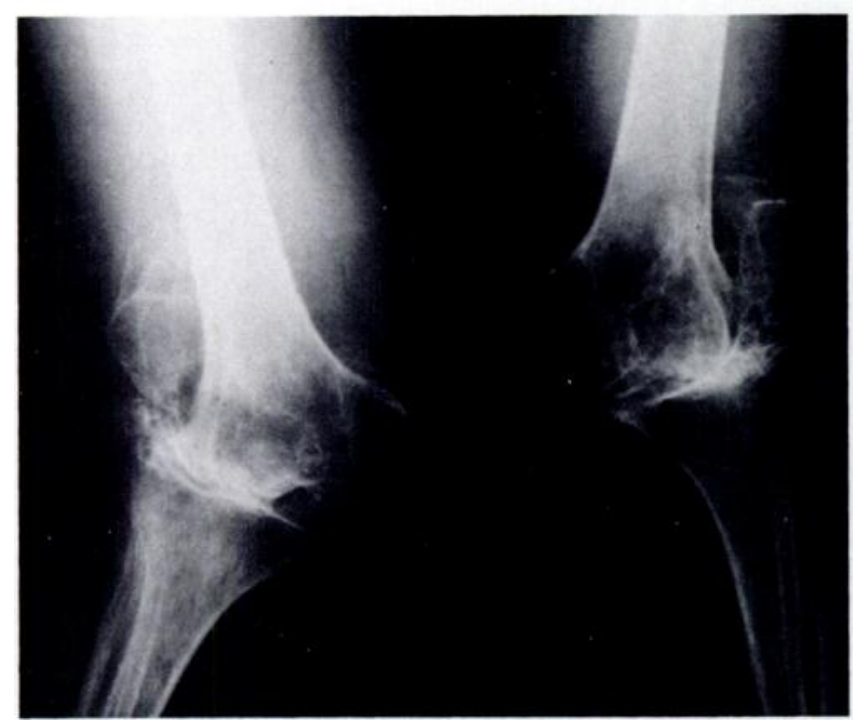

Fig. 5

\section{Complications}

Two knees developed deep infections involving the prosthesis. One patient had had a previous patellectomy through a transverse incision, and two years after prosthetic replacement the scar broke down exposing the prosthesis. Although the defect was closed, the wound, the prosthesis and eventually the tibia became infected with Pseudomonas. Although the prosthesis was not clinically loose, a mid-thigh amputation was performed. No evidence of loosening of either the femoral or the tibial component was found, and the femoral component could only be removed with great difficulty. It may well be that the extensor mechanism and skin were, in the absence of the patella, abraded by the prosthesis, leading to a breakdown of the transverse scar. However, the patient was later found to be sensitive to nickel and cobalt which may also have played a part.

The second case of deep infection occurred in a patient who had previously had a high tibial osteotomy fixed with a staple, which had not been removed at the time of prosthetic replacement. A sinus developed which extended down to the staple and to the prosthesis, but exploration revealed no evidence of loosening. The prosthesis functioned satisfactorily until the patient's death from renal failure two years after operation.

One patient (who had had a patellectomy because of painful subluxation) ruptured her patellar ligament; this was satisfactorily repaired. The opposite patella also subluxated but required no treatment. The patient who died in the first year after replacement also had a subluxated patella, but this had not required treatment.

One patient, who had had gross valgus instability and deformity before having both knees replaced (Figs 5 to 7), dislocated her patella; the patella of the other knee had been removed at the time of prosthetic replacement. This patient was one of the long-term survivors and both prostheses have functioned satisfactorily for 12 and 13 years respectively (Figs 8 to 10). She has had no pain

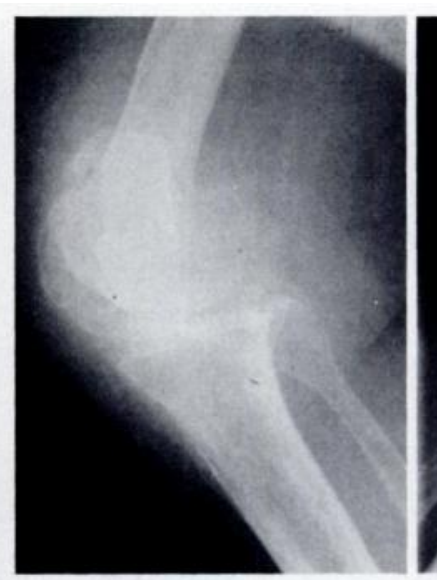

Fig. 6

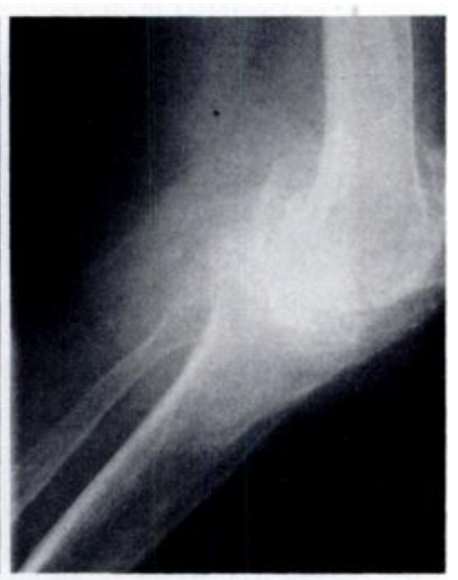

Fig. 7
Before replacement. Figure 5-Anteroposterior radiograph. Figure 6 Lateral radiograph of the left knee. Figure 7-The right knee. 

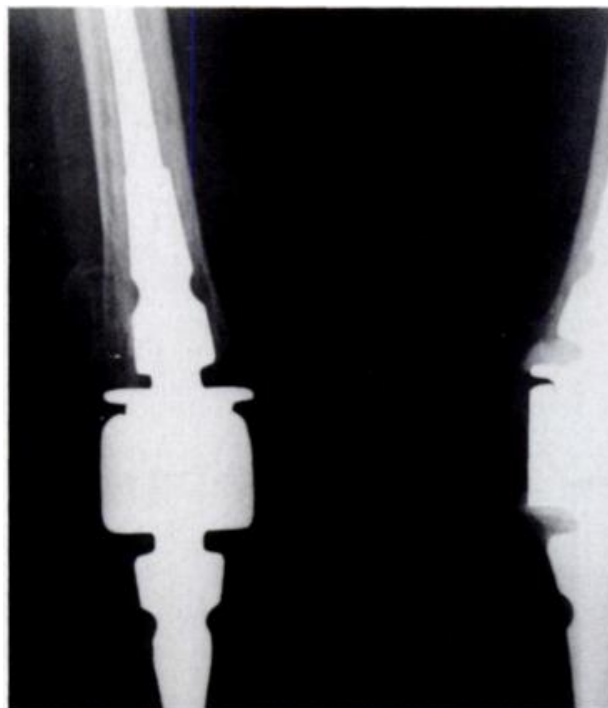

Fig. 8

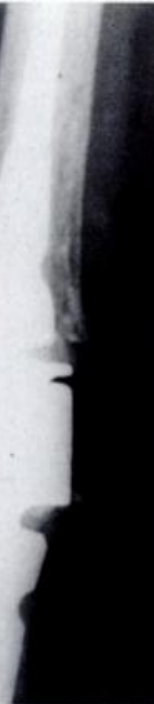

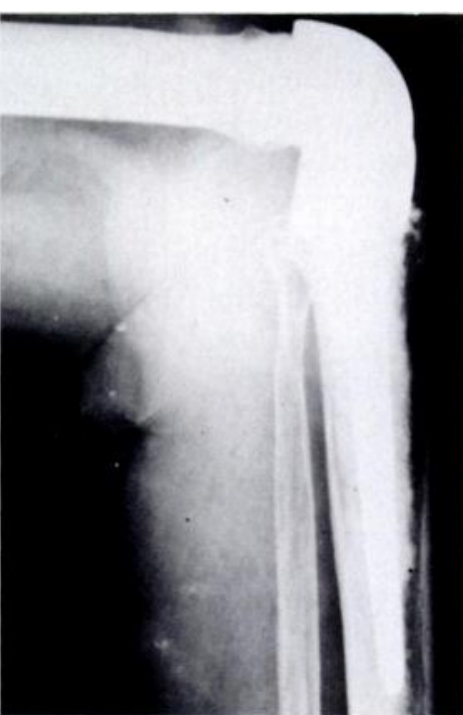

Fig. 9

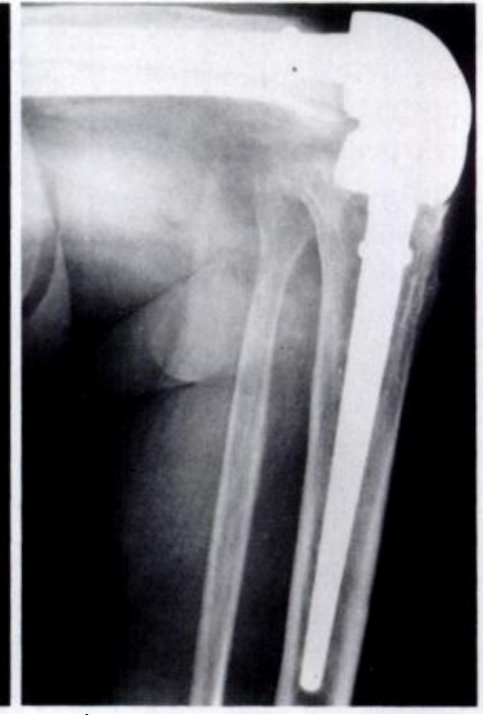

Fig. 10

Figure 8 Anteroposterior radiograph of both knees; the left knee had been replaced 12 years previously and the right knee 13 years previously. The right patella remains dislocated. Figure 9- Lateral radiograph of the left knee in flexion. Figure 10 - The right knee in flexion.

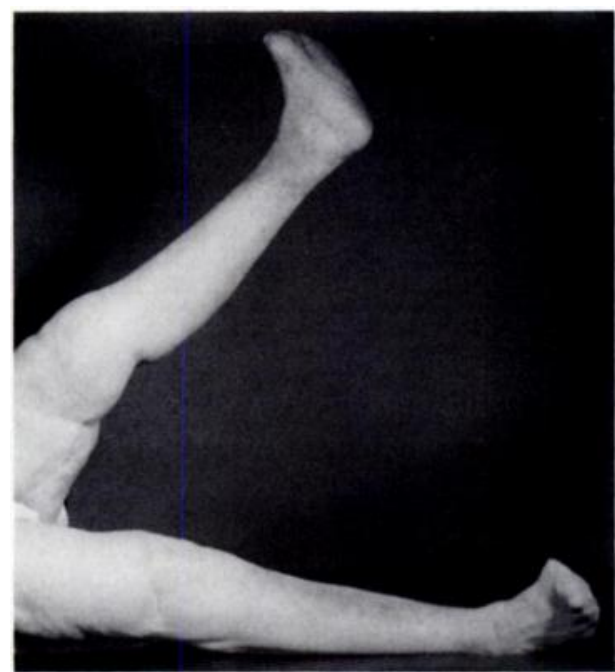

Fig. 11

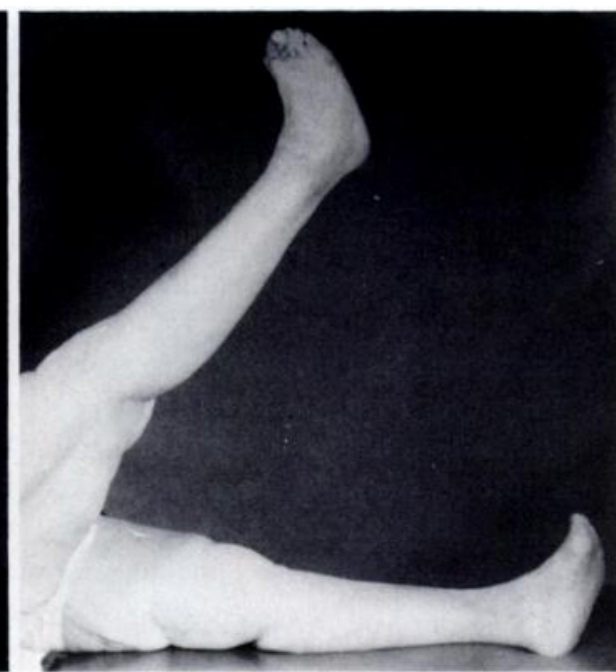

Fig. 12

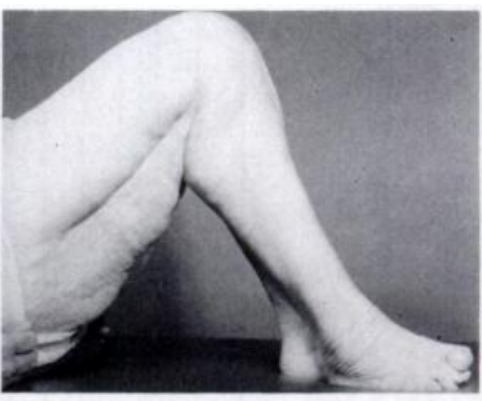

Fig. 13

Figures 11 and $12-$ Clinical photographs showing full active extension of both knees 12 and 13 years after replacement respectively. Figure 13-Flexion of both knees.

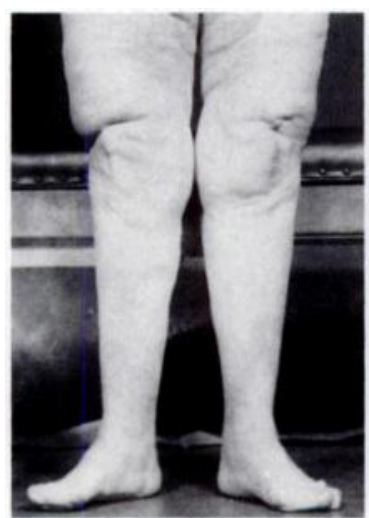

Fig. 14

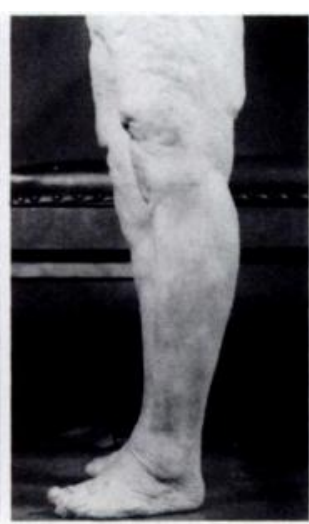

Fig. 15
Anteroposterior and lateral photographs of both knees 12 and 13 years after replacement. whatsoever and is able to extend both knees fully without significant lag (Figs 11 and 12); the right knee can be actively extended from full flexion, but the left, from which the patella was removed, cannot. Flexion exceeds $90^{\circ}$ on both sides (Fig. 13), and the knees are stable with no fixed flexion deformities (Figs 14 and 15).

One knee replacement was carried out in a 37-yearold woman with severe flexion deformities of both hips and both knees as a result of rheumatoid disease. Both hips had previously been replaced and one knee arthrodesed in $35^{\circ}$ of flexion. The replaced knee developed a flexion contracture and eventually became completely ankylosed in $40^{\circ}$ of flexion when the patient took to a wheelchair three years after operation.

None of the prostheses has broken, or become loose, and radiographs of the surviving knees show no evidence 
of bone erosion around the intramedullary stems. One patient, now 84 years old and suffering from Parkinson's disease in addition to rheumatoid arthritis, had her right knee replaced with an uncemented Walldius prosthesis in 1969, a year before replacement of her left knee with a Stanmore prosthesis. The right knee is painful and unstable with a $30^{\circ}$ varus deformity, and flexion is limited to $45^{\circ}$; the Walldius prosthesis is obviously loose (Fig. 16). This is in marked contrast to the Stanmore prosthesis which is pain-free, stable and in normal alignment, flexing to $90^{\circ}$ with no extension lag or fixed flexion. deformity.

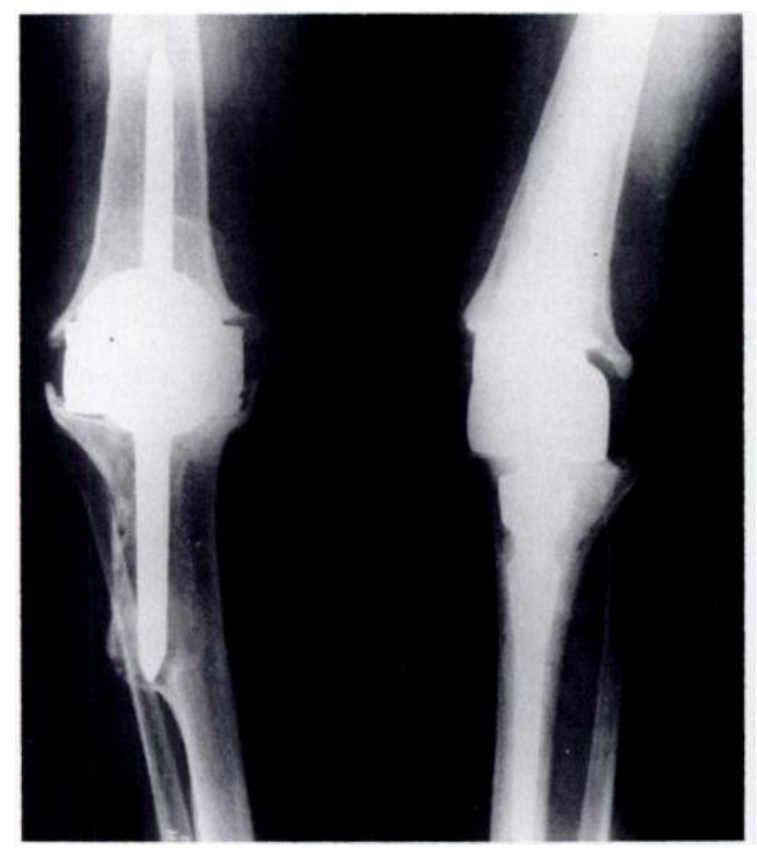

Fig. 16

Radiograph taken 12 years after the left knee was replaced with a Stanmore prosthesis and 13 years after the right knee was replaced with a Walldius prosthesis. The Walldius is obviously loose.

\section{DISCUSSION}

In our small series, the prototype of the Stanmore knee replacement relieved pain, corrected or reduced deformity, restored stability, and preserved or restored a painfree range of movement; the improvement noted one year after knee replacement was generally maintained or even increased over the next 9 years. Although five of the surviving 11 knees developed retropatellar pain, no patient found this disabling. All but two of the long-term survivors have remained fully weight-bearing for at least 10 years, and the absence of loosening over such a long period is in marked contrast to the experience reported with other constrained and unconstrained prostheses (Bargar, Cracchiolo and Amstutz 1980; Hui and Fitzgerald 1980; Wilson et al. 1980), but in accord with the results of massive prosthetic replacement described by Scales and Wright in 1981. Scales and Wright reported no case of loosening in 123 patients with bone tumours of the distal femur or tibia treated by major bone and joint replacement from July 1949 to July 1981.
The prosthesis used in our patients had long intramedullary stems $(17.78 \mathrm{~cm})$ set at an angle of $8^{\circ}$ to reproduce the average standing angle between the long axes of the femur and the tibia; many of the early constrained replacements lacked this refinement (Walldius 1957; Shiers 1960). In addition to their greater length, the stems also occupied the greater part of the medullary canals of the femur and the tibia, a fact now believed to be an important consideration in prosthetic design (Beckenbaugh and Ilstrup 1978; Sutherland $e t$ al. 1982). The body of the prosthesis was also larger than in the later design of the Stanmore prosthesis, which resulted in the load being distributed over a larger area of the resected surface of the femur and tibia (Figs 17 to 20). More bone was also removed from the lower end of the femur to accommodate the prosthesis; this effectively prevented the impingement of the posterior cortices of the femur and the tibia in full flexion, which may have been a factor in the loosening of other designs.

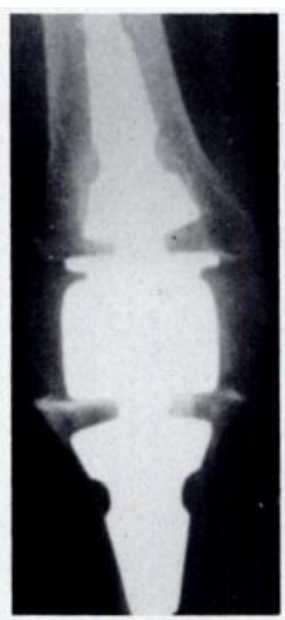

Fig. 17

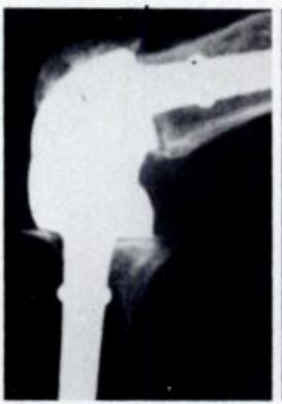

Fig. 19

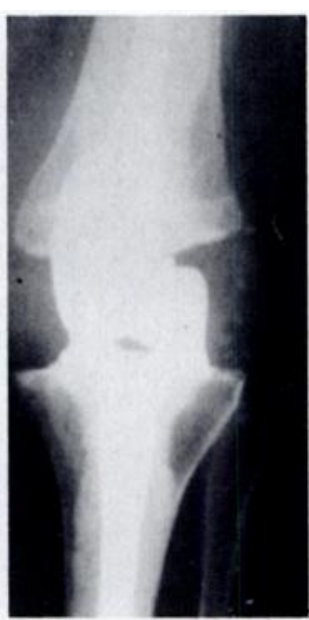

Fig. 18

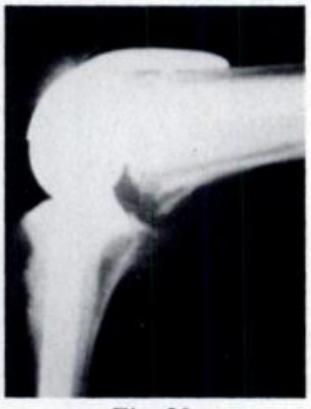

Fig. 20
Radiographs comparing Stanmore metal to metal prosthesis (Figs 17 and 19) with subsequent design of smaller dimensions with RCH 1000 bushes (Figs 18 and 20).

A fixed flexion deformity in the opposite knee seemed to predispose to the development of a fixed flexion deformity of similar magnitude in the replaced knee, and suggests that where pre-existing deformity exists, early prosthetic replacement of the second side should be carried out. Although this is a small series, the duration and completeness of the follow-up is greater than in any other reported series of replacements for 
arthritic knees. The clinical results and the incidence of types of knee replacement but also with prosthetic complications compare favourably not only with other replacement of the hip (Sutherland et al. 1982).

We wish to thank Mr S. Medcraft of OEC Orthopaedic Limited, who has been concerned over the years with the development of the Stanmore total knee replacement. We are also indebted to the staff of the Medical Records and Medical Photographic Departments of St Bartholomew's Hospital and the Royal National Orthopaedic Hospital, and to the staff of the Department of Biomedical Engineering, Institute of Orthopaedics, who have assisted in many ways.

\section{REFERENCES}

Bargar WL, Cracchiolo A III, Amstutz HC. Results with constrained total knee prosthesis in treating severely disabled patients and patients with failed total knee replacements. J Bone Joint Surg [ Am] 1980;62-A:504-12.

Beckenbaugh RD, Ilstrup DM. Total hip arthroplasty: a review of three hundred and thirty-three cases with long follow-up. $J$ Bone Joint Surg $[A m] 1978 ; 60-A: 306-13$.

Burrows HJ. Presidential address. Major prosthetic replacement of bone: lessons learnt in seventeen years. J Bone Joint Surg [Br] 1968; 50-B:225-6.

Burrows HJ, Wilson JN, Scales JT. Excision of tumours of humerus and femur, with restoration by internal prostheses. J Bone Joint Surg [Br] 1975;57-B:148-59.

Hui FC, Fitzgerald RH Jr. Hinged total knee arthroplasty. J Bone Joint Surg [ Am] 1980;62-A:513-9.

Scales JT, Lettin AWF. The evolution of the Stanmore hinged total knee replacement. Int Congr Ser 1974;324:284-95.

Scales JT, Wright KWJ. Major bone and joint replacement using custom implants. In: Chao EY-S, Ivins JC, eds. Tumor prostheses for bone and joint reconstruction. New York: Thieme-Stratton, 1983: 149-68.

Shiers LGP. Arthroplasty of the knee: interim report of a new method. J Bone Joint Surg [Br] 1960;42-B:31-9.

Sutherland CJ, Wilde AH, Borden LS, Marks KE. A ten-year follow-up of one hundred consecutive Müller curved-stem total hip replacement arthroplasties. J Bone Joint Surg [ Am] 1982;64-A:970-82.

Walldius B. Arthroplasty of the knee using an endoprosthesis. Acta Orthop Scand 1957; Suppl 24:1-112.

Wilson JN, Lettin AWF, Scales JT. Twenty years of evaluation of the Stanmore hinged total knee replacement. Proceedings of a conference on total knee replacement. London: Institution of Mechanical Engineers, 1974; 214:61-7.

Wilson FC, Fajenbaum DM, Hill C, Venters GC. Results of knee replacement with the Walldius and geometric prostheses: a comparative study. $J$ Bone Joint Surg [ Am] 1980;62-A:497-503. 